\title{
The Effects of Perceived Organizational Culture of Early Childhood Education Institutions and Ego-resilience on Happiness in Early Childhood Teachers
}

\author{
Yu-Kyeong Lee1), Sung-On Hwang2)
}

\begin{abstract}
The purpose of this study was to determine the effects of perceived organizational culture of early childhood education institutions and ego-resilience on happiness in early childhood teachers. The survey was conducted in 300 teachers at early childhood education institutions in Incheon city. The collected data were statistically processed using an SPSS 20.0 program. Descriptive statistics was used to determine teachers' socio-demographic characteristics; Cronbach's coefficient was estimated for reliability of a the instruments. Pearson's correlation analysis was carried out to determine the correlation among research variables. Lastly, multiple regression analysis was performed to determine the relative impact of perceived organizational culture of early childhood education institutions and ego-resilience on happiness in early childhood teachers. The results of this study can be summarized as follows. First, significant positive correlation was found among all of perceived organizational culture of early childhood education institutions, ego-resilience, and happiness in early childhood teachers. Second, the relative impact of perceived organizational culture of early childhood education institutions and ego-resilience on happiness in early childhood teachers had meaningful explanatory power. These results suggest that perceived organizational culture of early childhood education institutions and ego-resilience can be important factors for happiness in early childhood teachers.
\end{abstract}

Keywords : Early Childhood, Teacher, Organizational Culture, Ego-resilience, Happiness

\section{Introduction}

Early childhood teachers are human resources that greatly affect the development of young children by staying with them for a long time in kindergarten and educating them, just like parents who are primary care-givers. It is important to maintain the happiness of the early childhood teacher because his/her stable and happy state of mind has a positive effect on the

Received(April 30, 2019), Review Result(1st: May 24, 2019, 2nd: July 29, 2019), Accepted(September 10, 2019)

1) (Student) 21999 Dept. Early Childhood Education, Incheon National Univ., Songdo-dong, Yeonsu-gu, Incheon, Korea

email: 001073889844@nate.com

2) (Professor, Corresponding Author) 21999 Dept. Early Childhood Education, Incheon National Univ., Songdo-dong, Yeonsu-gu, Incheon, Korea

email: hso@inu.ac.kr 
The Effects of Perceived Organizational Culture of Early Childhood Education Institutions and Ego-resilience on Happiness in Early Childhood Teachers

child's healthy attachment to the teacher and emotional development. However, today's early childhood teachers suffer from low social awareness in terms of professionalism and are under considerable stress due to problems such as excessive working hours, poor working conditions and low pay[1]. Since the happiness of early childhood teacher is directly linked to the well-being and emotional development of young children, the happiness of teacher must be guaranteed[1].

A prior study on the happiness of early childhood teachers showed that teachers with a high level of participated in what they were doing voluntarily and actively, performed their roles well with a high level of concentration, had a high level of understanding and job performance[2]. It was also found that the higher teacher's happiness, the more positively affects job satisfaction[2]. In addition, the happiness of teachers has been shown to have a positive influence on not only the teachers themselves, but also their fellow teachers, including young children in kindergarten[3]. Since the early childhood teachers' happiness affects their ability to perform their roles as teachers and their children directly and indirectly[4], we need to pay more attention to the teachers' happiness in order to provide a quality educational environment.

In order to examine the variables that affect teacher's happiness, the environmental factors of the working place to which the teacher belongs, as well as the personal factors of the teacher. This study attempts to find out the influence of the teacher's sense of happiness, focusing on the organizational culture that teachers are perceived to be environmental factors, and on the ego-resilience of the teachers' personal factors.

First of all, the concept and importance of organizational culture of early childhood education institutions is as follows. Organizational culture of workplace is a comprehensive concept that includes all values, norms, rituals, and knowledge shared by members of an organization[5], referring to values or ideologies, customs, norms, knowledge and skills shared by members of an organization[6]. When an early childhood teacher works in a place where the organizational culture supporting the change and development of teachers is formed, the teacher's happiness is particularly high[7]. Organizational culture of early childhood education institutions is important because they provide incentives for teachers to improve their professionalism and competence[8], improve teachers' sense of well-being and achieve organizational goals[9].

Next, the concept and importance of ego-resilience among the individual internal changes of the early childhood teacher are as follows. Ego-resilience refers to the flexible adaptability of the various problem situations a person will experience to provide objective insight and a 
variety of strategies for problem resolution so that they or others can have good results[10]. Ego-resilience is an important factor to be established as it provides the ability to adapt fully to changing circumstances and events, providing an teacher with the ability to accurately cope with and control stress in his or her situation. That is, an early childhood teacher with the high level of ego-resilience is a positive excuse for dealing with the problem situation positively, promoting a smooth human relationship, and promoting happiness[11].

As mentioned above, the organizational culture and ego-resilience of the early childhood education institution are important factors for the teachers' happiness, so it may be necessary to examine ways to enhance the teachers' happiness through these two factors. In addition to the recent study of sense of happiness, there is a high level of social interest in teachers ' happiness and related research is actively being conducted[12]. However, the study on the happiness of early childhood teachers is still insufficient, and no concrete and direct study has been conducted on how the organizational culture of early childhood education institutions and the ego-resilience of teachers are affected with respect to the sense of happiness of early childhood teachers. Therefore, in this study, we look at the relationship between organizational culture, ego-resilience and happiness of teachers, and verify the hypothesis concerning the relative influence of organizational culture and self-elasticity that affect the teacher's happiness. To carry out the objectives of this study, the following are the research hypotheses:

Hypothesis 1 . There are positive relationships among the organizational culture of childhood institution, ego-resilience of teachers, and happiness in teachers?

Hypothesis 2. The child care teacher's organizational culture of childhood institution and ego-resilience have positive effect on happiness in teachers?

\section{Method}

\subsection{Participants}

Among teachers at 70 institutions in kindergarten and daycare centers located in Incheon, 350 teachers who expressed their intention to participate in the research were distributed the questionnaire. But 300 teachers were selected as the final target of the study considering the suitability of the retrieved questionnaire. In the case of institutional types, 67.7 percent were private daycare centers, 11.7 percent were private kindergartens, 11.0 percent were national and 
The Effects of Perceived Organizational Culture of Early Childhood Education Institutions and Ego-resilience on Happiness in Early Childhood Teachers

public daycare centers and 9.7 percent were public kindergartens. For teachers' age, 42.0 percent were in their 40s, 23.3 percent were in their 30s, 19.3 percent were in their 20s and 15.3 percent were in their 50s and older. In terms of education experience, four to six years were 31.0 percent, seven to 10 years were 26.3 percent, less than three years were 24.0 percent, and more than 10 years were 18.7 percent. In the case of teaching positions, 85.3 percent were for head-teachers, 10.0 percent for auxiliary teachers, 4.7 percent for principals.

\subsection{Instrumentations}

\subsubsection{Organizational Culture of Early Childhood Education Institutions}

To assess organizational culture of early childhood education institutions of teachers, the measurement tools used in Ho-ju Lee(2013) study were used[13]. This instrument consisted of 4 items for 'collective culture', 4 items for 'developmental culture', 4 items for 'organizational culture', and 4 items for 'rational culture'. The questionaries included 16 items in 5-Likert scale ranging from 1 (strongly disagree) to 5 (strongly agree). The results of reliability analysis exhibited that the total reliability of the questionnaire is very high $(a=.92)$.

\subsubsection{Ego-resilience}

Hyun-jin Park's (1996) translation of the California Adult Q set (CAQ) from Klohnen's (1996) California Personality Inventory (CPI) was used to measure ego-resilience[14][15]. The instrument consisted of 9 items for 'self-confidence', 8 items for 'interpersonal efficiency', 10 items for 'optimistic attitude', and 2 items for 'anger control'. The questionaries included 29 items in 5-Likert scale. The total reliability of the questionnaire is very high $(a=.92)$.

\subsubsection{Happiness}

The Oxford Happiness Questionnaire (OHQ), which had been developed by Argyle (2001), translated by Seok-man Gwon (2011), and adapted by Young-ok Choi (2011), was used to measure teachers' happiness[16-18]. This instrument consisted of 10 items for the 'external happiness', 6 items for 'inner happiness', and 5 items for 'self-regulating happiness'. The questionaries included 21 items in 5-Likert scale. The total reliability of the questionnaire is very high $(a=.94)$. 


\subsection{Procedures}

A preliminary survey of 10 early childhood education teachers was conducted from June 1 to June 5, 2018 to find out the appropriateness and time required for the questionnaire. After confirming the appropriateness of the questionnaire through a preliminary survey, the questionnaire was sent to an institution that expressed its intention to participate in the research among kindergartens and daycare centers located in Incheon city from 25 July to 15 September 2018. A total of 350 copies of the questionnaire were distributed to teachers, and the final 300 copies were used for statistical analysis, except for those who gave missing and unsincere answers.

\subsection{Statistical Analysis}

The data collected in this study were analyzed using the SPSS 20.0 program. First, frequency and percentage were calculated to identify the general characteristics of the study target. The Cronbach's a coefficient was then calculated to review the reliability and feasibility of the research instruments. In addition, Pearson's correlation analysis was conducted to find out the relationship between teachers' perceived organizational culture of early childhood education institution, ego-resilience, and happiness. Finally, multiple regression analysis was conducted to find out the relative influence of the teachers' perceived organizational culture of early childhood education institution and ego-resilience on happiness.

\section{Results}

\subsection{Correlations Between Research Variables}

Pearson's Correlation Analysis was performed to identify the relationship between the perceived organizational culture of early childhood education institution and ego-resilience and happiness (see Table 1). First, there were positive relationships between the 3 sub-factors of perceived organizational culture of early childhood education institution variable(collective, developmental, organizational culture) and ego-resilience (Total) variable $(r=.19 \sim .35, p<.01)$. However, there was no significant relationship between rational cultural and ego-resilience variable. This results showed that high score on the teachers' perceived organizational culture of early childhood education institution except sub-factor (rational culture) means a high score on teachers' 
The Effects of Perceived Organizational Culture of Early Childhood Education Institutions and Ego-resilience on Happiness in Early Childhood Teachers

ego-resilience.

Next, there was a positive relationship between the ego-resilience (Total) variable and the happiness (Total) variable $(r=.56, p<.01)$. There were also positive relationships between the sub-factors of ego-resilience variable and the sub-factors of happiness variable $(r=.20 \sim .55$, $p \nless .01)$. In other words, a high score on the teachers' ego-resilience means a high score on happiness.

Finally, there were positive relationships between the sub-factors of the teachers' perceived organizational culture of early childhood education institution variable and the happiness variable and sub-factors variable $(r=.18 \sim .48, p<.01)$. In other words, a high score on the teachers' perceived organizational culture of early childhood education institution means a high score on happiness.

[Table 1] Results of Correlations between Research Variables

\begin{tabular}{|c|c|c|c|c|c|c|c|c|c|c|c|c|c|}
\hline \multicolumn{2}{|l|}{ Variables } & 1 & 2 & 3 & 4 & 5 & 6 & 7 & 8 & 9 & 10 & 11 & 12 \\
\hline $\begin{array}{c}\text { Perceived } \\
\text { organizational } \\
\text { culture of early } \\
\text { childhood } \\
\text { education } \\
\text { institution }\end{array}$ & 1 & $\begin{array}{c}1 \\
.64^{* *} \\
.51^{* *} \\
.24^{* *}\end{array}$ & $\begin{array}{c}1 \\
.59^{* *} \\
.42^{* *}\end{array}$ & $\begin{array}{c}1 \\
.72^{* *}\end{array}$ & 1 & & & & & & & & \\
\hline Ego-resilience & 7 & $\begin{array}{l}.21^{* *} \\
.24^{* *} \\
.25^{* *} \\
.27^{* *} \\
.27^{* *}\end{array}$ & $\begin{array}{l}.23^{* *} \\
.34^{* *} \\
.35^{* *} \\
.27^{* *} \\
.35^{* *}\end{array}$ & $\begin{array}{l}.19^{* *} \\
.11 \\
.22^{* *} \\
.12^{*} \\
.19^{* * *}\end{array}$ & $\begin{array}{l}-.04 \\
-.06 \\
-.03 \\
-.11 \\
-.06\end{array}$ & $\begin{array}{c}1 \\
.77^{* *} \\
.76^{* *} \\
.43^{* *} \\
.93^{* *}\end{array}$ & $\begin{array}{c}1 \\
.62^{* *} \\
.42^{\text {** }} \\
.88^{\text {** }}\end{array}$ & $\begin{array}{c}1 \\
.40^{* *} \\
.88^{* *}\end{array}$ & $\begin{array}{c}1 \\
.56^{* *}\end{array}$ & 1 & & & \\
\hline Happiness & $\begin{array}{l}10 \\
11 \\
12\end{array}$ & $\begin{array}{l}.33^{* *} \\
.18^{* *} \\
.34^{* *} \\
.34^{* *}\end{array}$ & $\begin{array}{l}.41^{* *} \\
.32^{* *} \\
.39^{* *} \\
.44^{* *}\end{array}$ & $\begin{array}{l}.40^{\text {** }} \\
.31^{\text {** }} \\
.48^{\text {** }} \\
.45^{\text {** }}\end{array}$ & $\begin{array}{l}.26^{* *} \\
.19^{* *} \\
.41^{* *} \\
.32^{* *}\end{array}$ & $\begin{array}{l}.46^{* *} \\
.48^{* *} \\
.38^{* *} \\
.51^{* *}\end{array}$ & $\begin{array}{l}.43^{* *} \\
.39^{* *} \\
.30^{* *} \\
.43^{* *}\end{array}$ & $\begin{array}{l}.51^{\text {** }} \\
.55^{\text {** }} \\
.42^{\text {** }} \\
.57^{\text {** }}\end{array}$ & $\begin{array}{l}.28^{* *} \\
.20^{* *} \\
.37^{* *} \\
.32^{* *}\end{array}$ & $\begin{array}{l}.51^{\text {** }} \\
.51^{\text {** }} \\
.42^{\text {** }} \\
.56^{* *}\end{array}$ & $\begin{array}{c}1 \\
.69^{* *} \\
.67^{* *} \\
.94^{* *}\end{array}$ & $\begin{array}{c}1 \\
.54^{* *} \\
.83^{* *}\end{array}$ & $\begin{array}{c}1 \\
.82^{* * *}\end{array}$ \\
\hline
\end{tabular}

$1=$ collective culture, $2=$ developmental culture, $3=$ organizational culture, $4=$ rational culture,

$5=$ self-confidence, $6=$ interpersonal efficiency, $7=$ optimistic attitude, $8=$ anger control, $9=$ ego-resilience(Total),

$10=$ external happiness, $11=$ inner happiness, $12=$ self-regulating happiness, $13=$ happiness(Total)

${ }^{*} p<.05,{ }^{* *} p<.01$

\subsection{Regression Results of Independent Variables for Dependent Variable}

The relative impact of early childhood teachers' perceived organizational culture of early childhood education institution and ego-resilience on their happiness had meaningful 
explanatory power (see Table 2). The result also indicated that the overall regression model is statistically significant $(F=36.81, p<.001)$. In this case, $51 \%$ of variance in independent variables is explained by the regression model $\left(R^{2}=.51\right)$. Such sub-factors as rational culture in perceived organizational culture of early childhood education institution, self-confidence and optimistic attitude in ego-resilience was found to have a positive influence on teachers' happiness. It was found to be highly influential in the order of teachers' optimistic attitude $(\beta$ $=.39, p<.001)$, rational culture of institution $(\beta=.26, p<.001)$, and teachers' self-confidence $(\beta=.20$, $\mathrm{p}<.05)$.

[Table 2] Results of Multiple Regression Analysis

\begin{tabular}{|c|c|c|c|c|c|c|c|}
\hline \multirow{2}{*}{\multicolumn{2}{|c|}{ Independent Variables }} & \multicolumn{6}{|c|}{ Happiness (Dependent Variable) } \\
\hline & & \multirow[b]{2}{*}{.26} & $\beta$ & $t$ & $F$ & $R$ & $R^{2}$ \\
\hline \multirow{4}{*}{$\begin{array}{c}\text { Perceived } \\
\text { organizational } \\
\text { culture of early } \\
\text { childhood } \\
\text { education } \\
\text { institution } \\
\end{array}$} & \multirow{4}{*}{$\begin{array}{c}\text { collective culture } \\
\text { developmental culture } \\
\text { organizational culture } \\
\text { rational culture }\end{array}$} & & .06 & 1.13 & \multirow{8}{*}{$36.81^{\text {twot }}$} & \multirow{8}{*}{.71} & \multirow{8}{*}{.51} \\
\hline & & .15 & .04 & .62 & & & \\
\hline & & .31 & .08 & 1.11 & & & \\
\hline & & .82 & .26 & $4.04^{*+* *}$ & & & \\
\hline \multirow{4}{*}{ Ego-resilience } & \multirow{4}{*}{$\begin{array}{c}\text { self-confidence } \\
\text { interpersonal efficiency } \\
\text { optimistic attitude } \\
\text { anger control }\end{array}$} & .44 & .20 & $2.47^{*}$ & & & \\
\hline & & -.02 & -.01 & -.13 & & & \\
\hline & & .87 & .39 & $5.90^{\text {*kt }}$ & & & \\
\hline & & .36 & .06 & 1.24 & & & \\
\hline
\end{tabular}

${ }^{*} p<.05, \quad{ }^{* * *+} p<.001$

\section{Conclusion}

This study sought to identify factors that affect the happiness of early childhood teachers in order to explore ways to increase teachers' happiness. The results of this study can be summarized as follows. First, as for the correlation among teachers' perceived organizational culture of their workplace and teachers' ego-resilience and happiness, significant positive correlation was found between organizational culture of workplace and ego-resilience, between organizational culture of workplace and happiness, and between ego-resilience and happiness. Second, the impact of organizational culture of early childhood education institutions and teachers' ego-resilience on their happiness accounted for about $51 \%$, which was statistically significant. Among the sub-factors for the independent variables, rational culture among the sub-factors for organizational culture and self-confidence and optimistic attitude among those for ego-resilience statistically significantly affected teachers' happiness; optimistic attitude, followed by rational culture and self-confidence, had the strongest relative impact. 
The Effects of Perceived Organizational Culture of Early Childhood Education Institutions and Ego-resilience on Happiness in Early Childhood Teachers

This study demonstrated that teachers' happiness was strongly affected by their optimistic attitude as well as rational culture of their workplace as well as by their self-confidence. it is necessary to create an organization culture with a cooperative and reasonable working atmosphere, closeness and trust, active exchange among the members of the organization and smooth human relations of workplace for the teachers. It is also believed that the development and application of relevant training programs is required to enhance the ego-resilience of teachers. Given that this study only conducted surveys on teachers and analyzed data, subsequent studies will require more objective, more relevant and intensified studies by studying various methods, such as in-depth interviews, participation observation methods and interviews of teachers.

\section{Acknowledgement}

This article is a part of Yu-Kyeong Lee's master's thesis submitted in 2019

\section{References}

[1] J. J. Cha and H. R. Lee, An Exploration of the Impact of Burnout and Emotional Labor on Happiness of Early Childhood Teachers, The Journal of Korea Open Association for Early Childhood Education, (2015), Vol.20, No.2, pp.375-393, UCI: G704-000666.2015.20.2.014

[2] M. J. Jung, S. Y. Lee, and J. Y. Shin, The Effects of Demographic Factors, Health Perception, Teacher Efficacy, Enthusiasm for Teaching Profession on the Happiness of Preschool Teachers, Asia-pacific Journal of Multimedia Services Convergent with Art, Humanities, and Sociology, (2016), Vol.6, No.11, pp.23-36, DOI: 10.35873 /ajmahs.2016.6.11.003

[3] K. M. Go, S. K. Lee, and S. K. Shim, The Relationship between Early Childhood Teachers' Teaching Flow and Their Happiness and Degree of Professional Development, The Journal of Korean Teacher Education, (2014), Vol.31, No.1, pp.69-94, DOI: 10.24211/tjkte.2014.31.1.69

[4] J. H. Han, The Impact of Self-Esteem and Professional Recognition on Early Childhood Teachers' Happiness, Early Childhood Education Research \& Review, (2014), Vol.18, No.4, pp.271-287, UCI: G704-000814.2014.18.4.009

[5] S. B. Lee and H. S. Hwang, The Influence of The Organizational Culture of a Daycare Center and Creative Personality on Happiness in Daycare Teachers, Journal of Future Early Childhood Education, (2016), Vol.23, No.2, pp.137-156, UCI: G704-000819.2016.23.2.013

[6] H. R. Lee and J. J. Cha, The Relationship between Organizational Climate, Infant Teachers' Self-determination, and Teacher Happiness, The Journal of Korea Open Association for Early Childhood 
[7] Y. E. Kim, The Effects of the Organizational Culture of a Daycare Center on the Happiness and Self-Leadership of Childcare Teachers, Journal of Early Childhood Education \& Educare Welfare, (2014), Vol.18, No.4, pp.319-340, UCI: G704-002073.2014.18.4.010

[8] H. K. Youn, Analysis on Teaching Culture in the Kindergarten, Korean Journal of Early Childhood Education and Care, (2008), Vol.1, No.1, pp.83-99.

[9] J, A. Kim and J. H. Lee, Organizational Culture of Child Care Centers Perceived by Child Care Practitioners, The Korea Association of Child Care and Education, (2008), No.55 pp.119-149, UCI: G704-000724.2008..55.004

[10] J. Y. Yoo and H. J. Hwang, The Effects of Ego-resilience and Professionalism Awareness on Occupational Stress in Early Childhood Teachers, Journal of Korean Child Care and Education, (2014), Vol.10, No.1, pp.131-146, DOI: $10.14698 / \mathrm{jkcce} .2014 .10 .1 .131$

[11] H. I. Hwang, J. H. Tack, and S. H. Hong, Impact of Resilience, Teacher Efficacy, and Job Satisfaction on Happiness in Early Childhood Teachers, Early Childhood Education Research \& Review, (2013), Vol.17, No.3, pp.411-432, UCI: G704-000814.2013.17.3.020

[12] M. S. Song, An Analysis of the Research Trend of Theses about Early Childhood Teacher`s Happiness, Journal of Children's Media \& Education, (2014), Vol.13, No.3, pp.149-169.

[13] H. J. Lee, Impact of Organizational Culture and Director's Transformational Leadership on Happiness and Teacher Efficacy among Kindergarten Teachers, Pusan National University, Unpublished Master's Thesis, (2013)

[14] H. J. Park, Perceived Stress, Response, and Depression based on Self-elasticity, Korea University, Unpublished Master's Thesis, (1996)

[15] E. C. Klohnen, Conceptual Analysis and Measurement of the Construct of Ego-resiliency, Journal of Personality and Social Psychology, (1996), Vol.70, No.5, pp.1067-1079, DOI: 10.1037//0022-3514.70.5.1067

[16] M. Argyle, The Psychology of Happiness, Routledge, (2001)

[17] S. M. Gwon, A Positive Personality: A Perspective of Positive Psychology, Hakjisa, (2011)

[18] Y. O. Choi, Analysis of the Relationship between Social Problem Solving Ability, Job Stress and Happiness by Teachers' Multidimensional Perfectionism, Kyung Sung University, Unpublished Doctoral's Thesis, (2011) 